\title{
GENETIC DETERMINATION OF ESTERASES OF SYNGENS 1 AND 8 IN PARAMECIUM AURELIA
}

\author{
ALAN CAVILL and IAN GIBSON \\ School of Biological Sciences, University of East Anglia, Norwich
}

Received 18.iii.71

\section{INTRODUCTION}

STARGH gel electrophoresis has been used to detect protein variations in many different organisms. The esterases and some mitochondrial enzymes of different stocks and syngens of Paramecium have been compared (Tait, 1970a, $b$; Allen, Byrne and Gronkite, 1971; Allen and Gibson, 1971). There was a general lack of variation between the esterases and mitochondrial enzymes of the stocks within a syngen although variations between syngens were common. In order to determine if these enzymes are under genetic control it is essential to carry out a breeding analysis between the variants to determine the inheritance pattern in subsequent generations. Genetic exchange does not occur to any extent between syngens so that the genetic basis of the syngen differences cannot be determined directly. However, the stocks within a syngen can mate and then a genetic analysis of the variations is possible. In this paper we have applied such an analysis to the esterase variants found in syngens 1 and 8 . There are many more variant stocks in syngen 2 and the genetic basis for these will appear in relation to an ecological study of syngen 2 from a Norfolk pond.

In Paramecium four classes of esterases have been disclosed in all syngens. Three of these classes-A, B and the cathodal variety $C$ have been studied in relation to the variants. The A esterases react with $\alpha$-naphthyl propionate, but not with $\alpha$-naphthyl butyrate, B with both substrates but more readily with the propionate, type $\mathrm{C}$ with butyrate more rapidly than propionate and type $\mathrm{D}$ esterases split both substrates to the same extent. The $\mathrm{A}$ esterases are also isozymic and show greater esterase variation between syngens than do the B esterases or the $\mathrm{C}$ (Allen and Gibson, 1971). In this paper we will study the following variations:

(a) the A variant enzyme which appears in one stock of syngen 8; and

(b) the B and $\mathrm{C}$ variants which appear in one stock of syngen 1.

Our results show that each of these types of esterase is under single gene control.

\section{MATERIALS AND METHODS}

The stocks of paramecia used in these investigations are grown on axenic media. They are stocks 299 and 138 of syngen 8 and stocks 540 and 90 of syngen 1. Their geographical origins are indicated elsewhere (Allen and Gibson, 1971). They are maintained in test-tube culture by weekly isolation as described elsewhere (Rowe, Gibson and Cavill, 1971). One litre cultures were grown up from a $250 \mathrm{ml}$. culture at $27^{\circ} \mathrm{C}$. 


\section{Electrophoresis}

Paramecia were concentrated by centrifugation and extracts made by freeze thawing. Electrophoresis of homogenates was carried out on 11 per cent. starch gels as described elsewhere (Rowe, Gibson and Cavill, 1971). A esterases were visualised in a reaction mixture containing $\alpha$-naphthyl propionate, $B$ esterases in $\alpha$-naphthyl butyrate and $G$ esterases in either mixture.

\section{Crosses}

These were carried out in axenic media by mixing together the mating types of the stocks from both syngens 1 and 8 . Mating types were obtained by taking cells from test-tube cultures grown at $27^{\circ} \mathrm{C}$. for 2 weeks, isolating single cells into depressions containing axenic medium, and allowing them to grow up for 1 day. Daily isolations of single cells into fresh media were carried out and after a large number of fissions had ensued (approx. 150) cells were examined to see if they underwent autogamy (Sonneborn, 1950). After this number of fissions autogamy occurred as seen by macronuclear breakdown. Following the detection of autogamy single cells were isolated (approx. 400) grown up in depression slides and placed in test-tubes containing axenic media. After 2 weeks' growth they were present in large numbers $(3000-4000 / \mathrm{ml}$.). $1 \mathrm{ml}$. samples of stocks from both syngens, from the tubes, were set up assuming each tube was pure for one mating type. After mixing the mating types, pairs formed within 24 hours at $27^{\circ} \mathrm{C}$. Out of 300 tubes of stock 540, for example, only 52 were able to participate in mating reactions. Furthermore only three tubes of one mating type were found and 49 of the other. Pairs were isolated into axenic medium and separated from each other after 12-20 hours. They were isolated in depressions and grown up into test-tube cultures. They were placed in $100 \mathrm{ml}$. axenic medium in $250-\mathrm{ml}$. flasks and after a further 2 weeks placed in $500 \mathrm{ml}$. of axenic medium in a 1-litre flask. The cultures were then grown up and used to prepare homogenates.

To test that genetic exchange had occurred the inheritance of the surface immobilisation antigens was monitored. Antisera was prepared against axenic cultures of the parental cells as carried out for bacterised cultures. Tests of the antisera for the immobilisation reaction were carried out as described elsewhere.

\section{Results}

\section{The $A$ esterase variant of syngen 8}

Stock 138 shows the typical esterase pattern of a syngen 8 stock (fig. $1(a)$ ). There are two A-type esterases, one $2 \mathrm{~cm}$. from the origin $\left(\mathrm{A}_{2}\right)$ and a faster variety $3 \mathrm{~cm}$. from the origin $\left(A_{1}\right)$. These are identified as $A$ types by their reaction with propionate but not butyrate. There is a $\mathrm{B}$-type esterase which is close to the slow A type. The $D$ type is $4 \mathrm{~cm}$. from the origin. There are three $\mathrm{C}$ types. The anodal appears as a doublet. The other is cathodal (see fig. 1).

Stock 299 shows a variant pattern for one of the A esterases (fig. I). It possesses the same, C, D, B esterases in terms of mobility and activity and also has the $A$ esterase $\left(A_{2}\right)$ at $2 \mathrm{~cm}$. as does stock 138 . However, the other A esterase $\left(A_{3}\right)$ only migrates $1 \mathrm{~cm}$. while stock 138 has the esterase $\left(A_{1}\right)$. 
This esterase at $1 \mathrm{~cm}$. in stock 299 is similar to that characteristic of syngens 1 , $5,3,7,12,13$ when grown in axenic medium. Crosses were carried out between stocks 299 and 138. Out of 243 successful isolations from pairs there were 129 deaths. A sample of the $F_{1}$ survivors ( 30 clones) which grew up were examined for their esterase patterns and showed $A$ types $A_{1}, A_{2}$ and $A_{3}$ esterases (fig. 1). Thirty $F_{1}$ extracts which were as concentrated as the parentals showed similar intensity of staining on the gels when incubated for the same length of time. A l:1 mixture of the two parental samples is shown in fig. l. The same bands were present as in the hybrid. The other esterases, $\mathrm{B}, \mathrm{C}$ and $\mathrm{D}$, are all present as in both parentals, but the $\mathrm{C}$ esterases in the natural hybrid are less active. $F_{1}$ clones were passed through autogamy

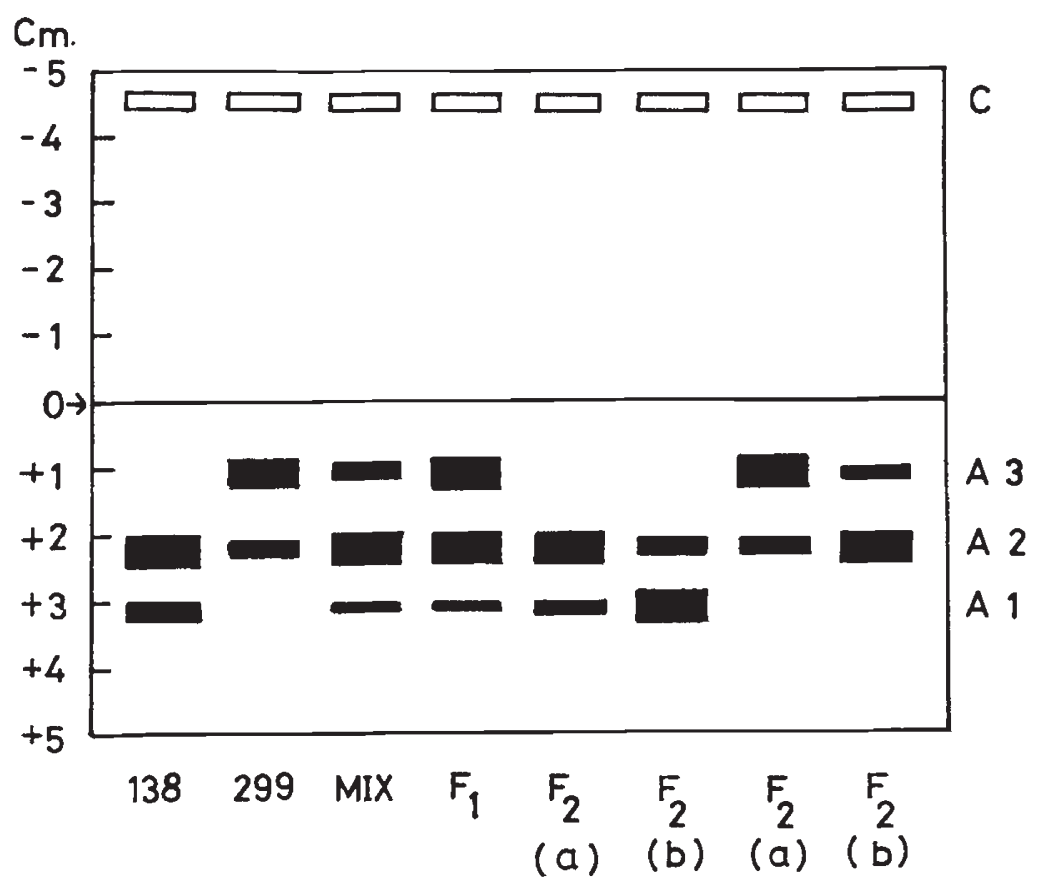

FIG. 1.-Esterases of stocks 138 and $299, F_{1}$ clones, an $F_{1}$ mixture and $F_{2}$ clones. Substrate is $\alpha$-naphthyl propionate. Types of esterases are represented by the following symbols: $\square=\mathrm{A}$ type $\square=\mathrm{C}$ type. The conditions of electrophoresis and staining of the gels was carried out as described in Rowe, Gibson and Cavill (1971).

and out of 243 such clones only 112 grew up (per cent. viability $=46$ ). These were examined for their esterase enzymes, the activity of these enzymes on the gels and also for their immobilisation antigen type. The results are shown in table 1 and fig. $1(a),(b)$. Here it can be seen that there is segregation (null hypothesis $1: 1, \chi(1)=0.9 ; \mathrm{P}=0.3-0.5)$ of the "parental" types in the $F_{2}$ for the variant $A$ esterases $\left(A_{3}\right.$ and $\left.A_{1}\right)$. This indicates that a single gene is responsible for the A esterase difference. There also appears to be a gene concerned with the activity of the A esterase (see fig. 1). Four $\mathrm{F}_{2}$ phenotypes appear in terms of activity of the A esterases. The parental " 299 " type can be subdivided into two classes, one with greater activity of the esterase $-A_{3}$ than of $A_{2}$. Another $F_{2}$ type has weak $A_{3}$ esterase and a strong $A_{2}$. These occur, as seen in table 1 , in proportions compatible with a 
$1: 1$ ratio (null hypothesis $1: 1, \chi_{(1)}^{2}=1.98 ; \mathrm{P}=0 \cdot 2-0 \cdot 1$ ). The " 138 " $\mathrm{F}_{2}$ type again shows two classes-one with a strong $\mathrm{A}_{2}$ esterase and a weak $A_{1}$ esterase. The other has a strong $A_{1}$ and a weak $A_{2}$ esterase. The two types appear in a $1: 1$ ratio $\left(\chi_{(1)}^{2}=2 \cdot 2 ; P=0 \cdot 2-0 \cdot 1\right)$. These results show that there are single gene differences between the stocks which affect the activity of the two $A$ esterases. The $F_{1}$ clones show equal activities of $A_{2}$

\section{TABLE 1}

The phenotypes of $F_{2}$ clones from a cross between stocks 299 and 138

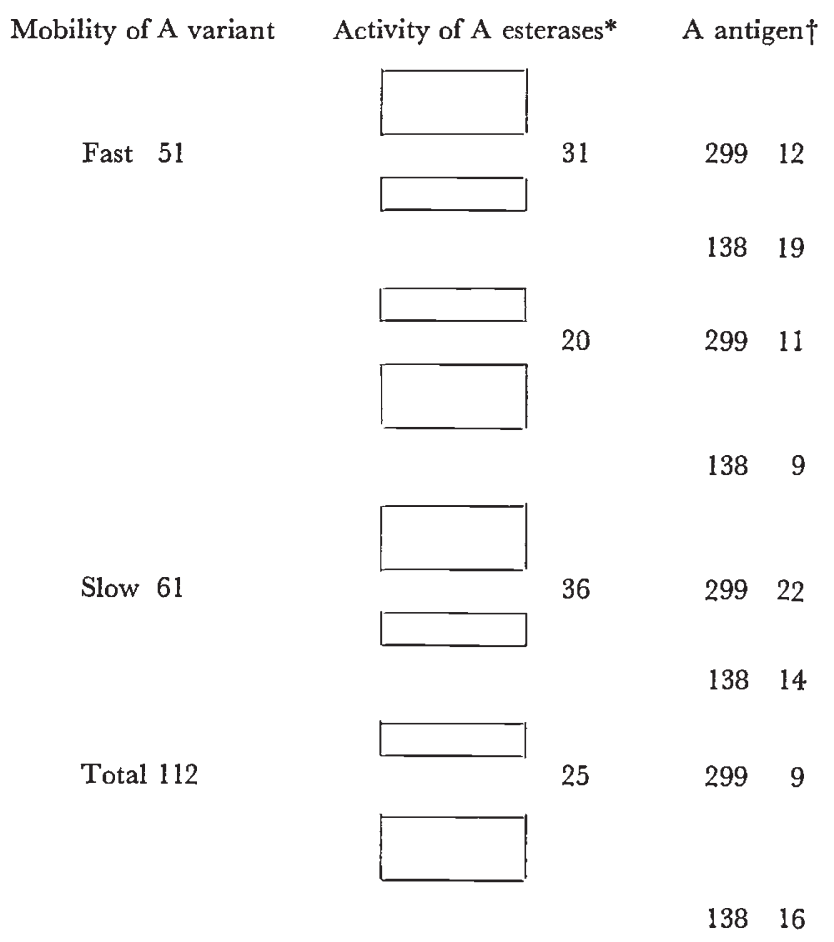

* Refers to intensity of staining. This is a measure of activity of enzyme and measure of protein concentration of extract.

$\dagger \mathrm{A}$ antiserum was prepared against stocks 299 and 138 growing at $27^{\circ} \mathrm{C}$. in axenic medium.

and $A_{3}$ but a weak $A_{1}$ esterase, suggesting that there is no effect of the activity gene from stock 299 in the heterozygote. The gene for the immobilisation antigens segregate in $\mathrm{F}_{2}$ clones as predicted from previous results in bacterised medium. Further $\chi^{2}$ analysis has been carried out to determine if there is independent segregation of these genes. Each $\mathrm{F}_{2}$ clone is independently determined in relation to the variation in mobility of the A esterase, the activity pattern of the A esterase and also the antigenic type. There is no evidence with these numbers for linkage of the genes.

\section{$B$ and $C$ esterase variants in syngen 1}

The normal pattern of a syngen 1 is exemplified by stock 90 . It possesses two A-type esterases at $1 \mathrm{~cm}$. and $2 \mathrm{~cm}$. from the origin. At $4 \mathrm{~cm}$. from the 
origin there is a D-type esterase. The sole B esterase occurs at $0.5 \mathrm{~cm}$. from the origin. Stock 540 differs from this pattern in two ways (fig. 2). It has a B-type esterase which migrates further from the origin and also possesses a $\mathrm{C}$ cathodal esterase which is missing from the stock 90 pattern.

Crosses were carried out between stock 540 and stock 90 . One hundred and twenty-three isolations from pairs were made but only six survived. These were grown up and tested for their esterases by starch gel electrophoresis (fig. 2). They were also classified as to their antigenic type. These $\mathrm{F}_{1}$ clones were always the same. They possessed one B-type esterase which was intermediate between the two positions of the parentals, the $\mathrm{C}$ cathodal esterase and both antigenic types shown by each of the parents. 1:1 mixtures

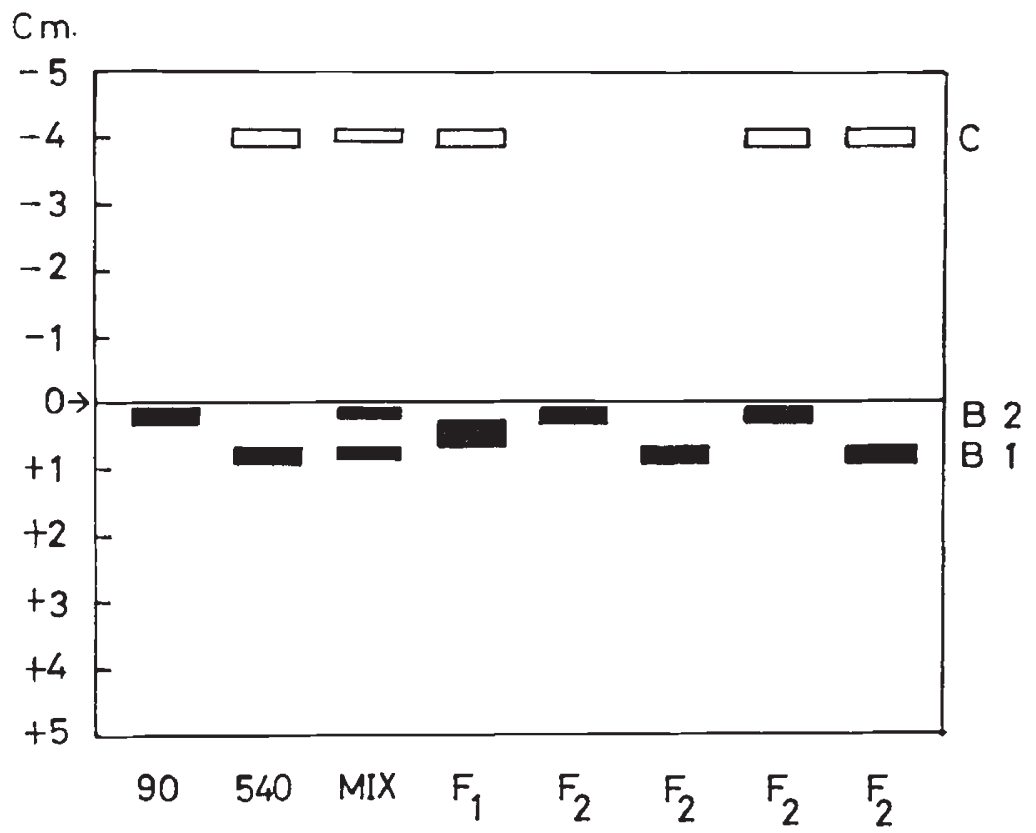

Fig. 2.--Esterases of stocks 540 and $90, \mathbf{F}_{1}$ clones, an $\mathbf{F}_{1}$ mixture and various $\mathbf{F}_{2}$ clones. Substrate is $\alpha$-naphthyl butyrate. Types of esterases are represented by the following symbols: $\square=\mathrm{B}$ type; $\square=\mathrm{C}$ type.

of samples from the two parents are shown in fig. 2. Here, unlike the $F_{1}$ clone, the two parental bands appeared. It is interesting in the natural hybrid that only one hybrid enzyme appears and there are no signs of the parental enzymes. $\mathrm{F}_{2}$ clones were produced following autogamy and again a high death rate was obtained- $-27 \cdot 5$ per cent. Only 89 clones survived and these were examined in the same manner as the $F_{1}$ clones. The results are shown in table 2. In fig. 2 the esterase patterns of the $\mathrm{F}_{2}$ clones are shown. The fast and slow $\mathrm{B}$ esterase appears in $\mathrm{F}_{2}$ clones in a ratio which is consistent with null hypothesis $1: 1, \chi(1)=1 \cdot 34 ; \mathrm{P}=0 \cdot 3-0 \cdot 2)$. The $\mathrm{C}$ esterase also showed segregation in the $\mathrm{F}_{2}$ clones for presence or absence-null hypothesis $1: 1, \chi_{(1)}^{2}=1 \cdot 90 ; P=0 \cdot 2-0 \cdot 1$. In fig. 2 we show the association of the C esterase with the " 540 " type and " 90 " type B esterase in $F_{2}$ clones. It was concluded that the differences between the presence or absence of 
$\mathrm{C}$ esterases and the mobility of $\mathrm{B}$ esterases were determined by single gene differences. The antigenic types also showed segregation in the $\mathrm{F}_{2}$ clones. Furthermore, there was independent segregation of the genes for B, C esterases and antigenic type. We conclude then that they are each determined by single loci on different chromosomes.

\section{TABLE 2}

The phenotypes of $F_{2}$ clones from a cross between stocks 540 and 90

\begin{tabular}{cccrr} 
B esterase & \multicolumn{2}{c}{ C esterase } & \multicolumn{2}{c}{ D antigen* } \\
Fast 50 & Presence & 20 & 540 & 6 \\
& & & 90 & 14 \\
& Absence & 30 & 540 & 17 \\
& & & 90 & 13 \\
Slow 39 & Presence & 18 & 540 & 12 \\
& & & 90 & 6 \\
& Absence & 21 & 540 & 12 \\
& & & 90 & 9
\end{tabular}

The $F_{1}$ survivors of autogamy were grown up; 89 survived and were typed for esterases and antigens. $30^{\circ} \mathrm{C}$.

* D antiserum was prepared against stocks 540 and 90 growing in axenic medium at

\section{Discussion}

The work reported here has disclosed single gene differences for the mobility of $\mathrm{A}$ and $\mathrm{B}$ esterases. We assign the symbols $E s A$ and $E s B$ for these genes. The genotypes of stock 90 and 540 are, therefore, $E_{s} B 90, E s B 540$. The genotypes of stock 138 are $E_{S} A 138$ and stock $299 E_{s} A$ 299. The genes which affect the activity of the esterases A 138 and A 299 we will call ac 138 and ac 299. The other genes we have identified are those involved with the presence or absence of $\mathrm{C}$ esterases in stocks 540 and 90 . These we will call $E_{s} C 540$ and $E s C$ 90. The $E s B$ genes and the $E s A$ genes show no evidence of dominance-both phenotypes appearing in the $\mathrm{F}_{1}$. In the case of the $E_{s} C$ gene the presence of the esterase appears to be dominant to the absence. The activity gene from the stock 299 does not appear to have any effect in the $\mathrm{F}_{1}$ on the $\mathrm{A}_{2}$ esterase.

The activity genes affect the $\mathrm{A}$ esterases of the syngen 8 stocks. Each stock has one A esterase with more activity than the other. When the gene determining this difference is introduced into combination with the genes determining mobility differences, then new relationships in terms of activity between the two $\mathrm{A}$ esterases may occur. Whereas the slower esterase $\mathbf{A}_{3}$ showed the greatest activity in stock 299, following the new gene combinations in the $F_{2}$, the faster esterase $A_{2}$ may now be most active, due to the action of the gene ac 138. The ac 299 gene causes the $\mathrm{A}_{1}$ enzyme to be the most active in one type of $\mathrm{F}_{2}$ clone. The possibility arises that the activity genes work by modifying subunit associations or by influencing multimer size.

These results supplement the work of others who have studied the relationship between genes and enzymes in Tetrahymena pyriformis and Paramecium. In Tetrahymena single genes have been shown to determine single esterase types and acid phosphatases (Allen, 1960; Allen, Misch and Morrison, 
$1963 a, b)$. In Paramecium aurelia nuclear genes have been shown to determine mitochondrial enzymes (Tait, 1968; 1970b).

With the discovery of gene control of these enzymes we have other gene markers for comparing the syngens of Paramecium in terms of gene and protein homologies (Allen and Gibson, 1971).

\section{Summary}

1. Variants in three different esterases (as defined by substrate specificity and inhibition experiments) have been detected in certain stocks of Paramecium.

2. Differences in the mobility of $A$ and $B$ esterases have in syngens 1 and 8 been shown to be under control of a single gene.

3. Genes which affect the activity of A esterases have been disclosed in syngen 8 .

4. Another gene in syngen 1 is responsible for the presence or absence of a C esterase.

5. These results will facilitate comparisons between syngens in terms of gene and protein homologies. work.

Acknowledgments.-Thanks are due to the Medical Research Council who financed this

\section{REFERENCES}

ALLEN, s. L. 1960. Inherited variations in the esterases of Tetrahymena. Genetics, 45, $1051-1070$.

ALLEN, S. L., BYRNE, B., AND GRONKITE, D. 1971. Intersyngenic variations in the esterases of bacterised Paramecium aurelia. Biochem. Genetics, 5, 135-151.

ALLEN, s. L., AND GIBSON, I. 1971. Intersyngenic variations in the esterases of axenic stocks of Paramecium aurelia. Biochem. Genetics, 5, 161-183.

ALLEN, s. L., MISGH, M., AND MORRISON, B. 1963a. Variations in the electrophoretically separated acid phosphatases of Tetrahymena. F. Hist. Cyto., 6, 706-719.

ALLEN, s. L., MISGH, M., AND MORRISON, B. 1963b. Genetic control of an acid phosphatase in Tetrahymena: formation of a hybrid enzyme. Genetics, 48, 1635-1658.

ROWE, E., GIBSON, I., AND CAVILL, A. 1971. The effects of growth conditions on the esterases of Paramecium aurelia. Biochem. Gen., 5, 151-161.

SONNEBORN, T. M. 1950. Methods in the general biology and genetics of Paramecium aurelia. F. Exp. Zoo., 113, 87-143.

TAIT, A. 1968 . Genetic control of $\beta$-hydroxybutyrate dehydrogenase of Paramecium aurelia. Nature, 219, 1941.

TAIT, A. 1970a. Enzyme variation between syngens of Paramecium aurelia. Biochem. Gen, 4, $461-470$.

TArT, A. 1970b. Genetics of NADP isocitrate dehydrogenase in Paramecium aurelia. Nature, 225, 181-182. 